University of Nebraska - Lincoln

DigitalCommons@University of Nebraska - Lincoln

Faculty Publications: Department of

Entomology

Entomology, Department of

$12-2011$

\title{
Cost-Effective Binomial Sequential Sampling of Western Bean Cutworm, Striacosta albicosta (Lepidoptera: Noctuidae), Egg Masses in Corn
}

\author{
S. Paula-Moraes \\ University of Nebraska-Lincoln,, silvana@cpac.embrapa.br \\ E. C. Burkness \\ University of Minnesota, burkn001@umn.edu \\ Thomas E. Hunt \\ Haskell Agricultural Laboratory, University of Nebraska, thunt2@unl.edu \\ Robert Wright \\ University of Nebraska--Lincoln, rwright2@unl.edu \\ Gary Hein \\ University of Nebraska--Lincoln, ghein1@unl.edu \\ See next page for additional authors \\ Follow this and additional works at: https://digitalcommons.unl.edu/entomologyfacpub \\ Part of the Entomology Commons
}

Paula-Moraes, S.; Burkness, E. C.; Hunt, Thomas E.; Wright, Robert; Hein, Gary; and Hutchinson, W. D., "Cost-Effective Binomial Sequential Sampling of Western Bean Cutworm, Striacosta albicosta (Lepidoptera: Noctuidae), Egg Masses in Corn" (2011). Faculty Publications: Department of Entomology. 330.

https://digitalcommons.unl.edu/entomologyfacpub/330

This Article is brought to you for free and open access by the Entomology, Department of at DigitalCommons@University of Nebraska - Lincoln. It has been accepted for inclusion in Faculty Publications: Department of Entomology by an authorized administrator of DigitalCommons@University of Nebraska - Lincoln. 


\section{Authors}

S. Paula-Moraes, E. C. Burkness, Thomas E. Hunt, Robert Wright, Gary Hein, and W. D. Hutchinson 


\title{
Cost-Effective Binomial Sequential Sampling of Western Bean Cutworm, Striacosta albicosta (Lepidoptera: Noctuidae), Egg Masses in Corn
}

\author{
S. PAULA-MORAES, ${ }^{1,2}$ E. C. BURKNESS, ${ }^{3}$ T. E. HUNT, ${ }^{4}$ R. J. WRIGHT, ${ }^{2}$ G. L. HEIN, ${ }^{5}$ \\ AND W. D. HUTCHISON ${ }^{3}$
}

\begin{abstract}
J. Econ. Entomol. 104(6): 1900-1908 (2011); DOI: http://dx.doi.org/10.1603/EC11127
ABSTRACT Striacosta albicosta (Smith) (Lepidoptera: Noctuidae), is a native pest of dry beans (Phaseolus vulgaris $\mathrm{L}$.) and corn (Zea mays L.). As a result of larval feeding damage on corn ears, S. albicosta has a narrow treatment window; thus, early detection of the pest in the field is essential, and egg mass sampling has become a popular monitoring tool. Three action thresholds for field and sweet corn currently are used by crop consultants, including $4 \%$ of plants infested with egg masses on sweet corn in the silking-tasseling stage, $8 \%$ of plants infested with egg masses on field corn with $\approx 95 \%$ tasseled, and $20 \%$ of plants infested with egg masses on field corn during mid-milk-stage corn. The current monitoring recommendation is to sample 20 plants at each of five locations per field ( 100 plants total). In an effort to develop a more cost-effective sampling plan for S. albicosta egg masses, several alternative binomial sampling plans were developed using Wald's sequential probability ratio test, and validated using Resampling for Validation of Sampling Plans (RVSP) software. The benefit-cost ratio also was calculated and used to determine the final selection of sampling plans. Based on final sampling plans selected for each action threshold, the average sample number required to reach a treat or no-treat decision ranged from 38 to 41 plants per field. This represents a significant savings in sampling cost over the current recommendation of 100 plants.
\end{abstract}

KEY WORDS binomial sampling, resampling software, western bean cutworm, benefit-cost ratio

Striacosta albicosta (Smith) first was described in Arizona (Smith 1887) as a native pest of dry beans (Phaseolus vulgaris L.) and corn (Zea mays L.) in the west-central United States (Hoerner 1948, Douglass et al. 1957). Before 1999, it was reported in Idaho, Kansas, Nebraska, Iowa, Utah, Colorado, Arizona, New Mexico, Texas, South Dakota, Wyoming, and Oklahoma (Appel et al. 1993). Beginning in 1999, however, S. albicosta larval infestations were documented in Minnesota sweet corn (O'Rourke and Hutchison 2000) and Iowa field corn (Rice 2000). Since then, S. albicosta has been found in Illinois; Missouri (Dorhout and Rice 2004); Wisconsin (Cullen and Jyuotika 2008); Indiana (Rice 2006); Mississippi; Ohio (DiFonzo and Hammond 2008); Pennsylvania (Tooker and Fleischer 2010); and Ontario and Quebec, Canada (Michel et al. 2010). Reasons for the

Mention of a proprietary product does not constitute an endorsement or a recommendation for its use by the universities associated with this research.

${ }^{1}$ Corresponding author, e-mail: silvana@cpac.embrapa.br.

${ }^{2}$ Department of Entomology, University of Nebraska-Lincoln, Lincoln, NE 68583.

${ }^{3}$ University of Minnesota, Department of Entomology, St. Paul, MN 55108 .

${ }^{4}$ Department of Entomology, University of Nebraska, NEREC Haskell Agricultural Laboratory, Concord, NE 68728.

${ }^{5}$ University of Nebraska-Lincoln, Doctor of Plant Health Program, Lincoln, NE 68583. apparent range expansion of S. albicosta remain unknown (Miller et al. 2009).

Striacosta albicosta is univoltine (Hagen 1962) and adults oviposit egg masses on the upper surface of corn leaves on the top half of the plant and in the whorl just before tassel emergence (Hagen 1962). Larvae feed for $\approx 31 \mathrm{~d}$, initially feeding on the anthers of the tassel, pollen, and then silks until they reach the fourth instar, when they move inside the ear and feed on kernels (Appel et al. 1993, Seymour et al. 2004). For each late instar per ear that survives to the dent stage, yield loss is estimated at $855.62 \mathrm{~kg} / \mathrm{ha}$ (Appel et al. 1993). Transgenic hybrids expressing the Bacillus thuringiensis (Bt) protein Cryl F (Herculex I, Dow AgroSciences, Indianapolis, IN; and Pioneer Hi-Bred International, Johnston, IA) provides adequate level of protection against S. albicosta feeding damage. However, these hybrids are not immune to S. albicosta and some ear feeding damage may occur (Eichenseer et al. 2008). In 2010, Bt corn hybrids with pyramided genes encoding Cryl F/CrylAb (Optimum Intrasect Insect protection, DuPont/Pioneer, Johnston, IA) and CrylA.105/ Cry2Ab2/Cry1 F (SmartStax Genuity, Monsanto, St. Louis, MO) also were commercially available. These hybrids are expected to be more efficacious against $S$. albicosta (DiFonzo and Cullen 2010).

Despite the availability of the transgenic technology, many Lepidopteran resistant transgenic hybrids 
are not efficacious against S. albicosta and there is still significant corn acreage that is not planted to $B t$ corn each year (Hutchison et al. 2010), including non-Bt sweet corn in the upper Midwest. This corn must be scouted and managed using thresholds and conventional insecticides (Seymour et al. 2004, Cullen and Jyuotika 2008). Traditionally, NE Integrated Pest Management (integrated pest management [IPM]) guidelines have indicated that 100 plants should be sampled, on average, for S. albicosta egg masses or larvae for making treat, no-treat decisions in corn. Although likely effective, this guideline is time-consuming and has presented obstacles to management of this insect. In addition, field experience and preliminary data suggest that a smaller sample size might be possible. Practical, cost-effective arthropod monitoring and sampling plans are critical elements of an IPM program that provide a foundation for determining when control measures should be applied.

Several economic, or action thresholds have been proposed for S. albicosta in corn. A common threshold used for field corn is $8 \%$ of the plants infested with egg masses on corn that is at least 95\% tasseled (Seymour et al. 2004, Peairs 2006). Rice (2007) summarized more recent thresholds that consider higher corn prices and suggested halving the $8 \%$ threshold to $4 \%$; a threshold of $5 \%$ of the plants with egg masses or small larvae on plants ranging from silking to early milk stage (R1-R3) also has been suggested. Finally, a threshold of $20 \%$ of the plants infested with egg masses at mid-milk stage (R3) also has been recommended (Rice 2007). Cullen and Jyuotika (2008) recommend a threshold of $4 \%$ of the plants with egg masses or small larvae in sweet corn, which is historically more valuable than field corn. The nominal threshold associated with these sampling plans could be viewed as an action threshold, as it is not directly associated with an economic injury level (EIL). However, an action threshold based on experience, and built upon numerous field observations can be very effective for a variety of IPM programs (Nault and Shelton 2010). For S. albicosta, and regardless of the desired threshold, the recommendations have required a fixed sample size of 100 plants per field (Rice 2006).

A binomial sequential sampling plan represents a one time-saving option (Kuno 1991, Jones 1994) that allows one to determine only the presence or absence of the pest. For S. albicosta, this approach implies that plants only would be examined until one egg mass is found (tally threshold of one), and not evaluate the number of egg masses per plant; samplers can then move on to the next plant (Binns et al. 2000). Moreover, the number of samples is not fixed in advance, and the pest population is classified as an economic or noneconomic density after a cumulative number of the samples are examined in the field (Hutchison 1994).

The objective of this study was to assess the potential for developing binomial sequential sampling plans for S. albicosta egg masses that could be more costeffective than the fixed-sample size monitoring currently in place. Three sampling plans were developed that consider the action thresholds currently used in the U.S. Corn Belt $(4,8$, and $20 \%$ of plants infested with one or more egg masses) for both field and sweet corn.

\section{Materials and Methods}

Egg masses of S. albicosta were sampled in a total of 70 commercial corn fields: 34 fields were sampled in 2005, 20 fields in 2006, and 16 fields in 2007 in southwest Nebraska and northeast Colorado. Fields were planted with Bt transgenic corn (Herculex) expressing the Cryl $\mathrm{F}$ toxin and non-Bt commercial field corn. The two types of hybrids ( $B t$ and non- $B t$ ), were planted in alternating strips of 4-12 rows each (typically six or eight) in the center of the fields. The remainder of the fields were planted to a herculex or nonherculex variety. All fields were under centerpivot irrigation and conventional agronomic practices were followed for the region. In each field, at least three and at most 10 sites were sampled in a transect across the field and the number of egg masses was counted on each of 20 consecutive plants per sampling site.

Spatial Distribution of Egg Masses. The relationship between the mean and variance was tested using Taylor's power law (TPL; Taylor 1961) to describe the dispersion pattern of $S$. albicosta egg masses in the corn. The effect of $B t$ and non-Bt corn on S. albicosta oviposition preference was tested by comparing the proportion of plants infested with egg masses between the two hybrids in each field (Proc Glimmix, SAS Institute 2009).

Binomial Sampling. The binomial sampling plan was developed using Wald's sequential probability ratio test (Wald 1947), and validated using Resampling for Validation of Sampling Plans (RVSP) software (Naranjo and Hutchison 1997). As discussed by Young and Young (1998), for designing Wald's sequential sampling plan the following information is necessary: 1) economic threshold, 2) safety level (the lower and upper bounds around economic threshold), 3) probabilities of type I and II errors and $\alpha$ and $\beta$, and 4) and the distribution of the pest to be sampled. In presence or absence sampling, the binomial distribution is the parametric form of the distribution. The binomial classification is used to create the most cost-efficient sampling plan for making pest management decisions for WBC.

After removing data sets with a mean S. albicosta egg mass density of zero, 55 of the 70 field data sets were used in the analysis. Several parameters were established to conduct Wald's binomial sequential probability ratio test. The number of resampling iterations for each field's data set was set at 500, the sampling was done with replacement, and the minimum sample size was defined as 20 sample units (plants) for each simulation (Naranjo and Hutchison 1997). The tally threshold was set at one S. albicosta egg mass, which is the number of egg masses required for the sample to be defined as infested.

Three different S. albicosta sampling plans were developed using thresholds of $4 \%$ of plants infested 
with egg masses for silking-blister-early milk-stage corn (Cullen and Jyuotika 2008); 8\% of plants infested with S. albicosta egg masses on corn at least $95 \%$ tasseled (Seymour et al. 2004, Peairs 2006); and 20\% of plants infested with S. albicosta egg masses for midmilk-stage corn (Rice 2007). For each threshold at least two different upper and lower boundaries were tested that represented the proportion of plants infested with S. albicosta egg masses (Jones 1994). For the $4 \%$ threshold, three different ranges of variation were simulated (Burkness and Hutchison 2009). Two ranges of variation were similar and symmetric in lower and upper bounds (0.01-0.07 and 0.02-0.06). Because the 0.02-0.06 range of variation for the 4\% threshold resulted in an ASN of 100 plants (current recommendation) a third sampling plan simulation was run. The boundaries of the third plan were asymmetric; with the lower bound at 0.03 and upper bound at 0.05 . For the 8 and $20 \%$ thresholds, the ranges of variation were symmetric. The lower and upper bounds were 0.04 and 0.05 from each threshold. These boundaries were necessary for the calculation for the sequential model and final stop lines (treat or no-treat decision lines) for the Wald's binomial sequential probability ratio test. The $\alpha$ value (type I error) was set at 0.10 (Binns 1994). The $\beta$ value (type II error) was set at 0.05 .

The RSVP software used a uniform random number generator to select samples from the S. albicosta egg mass data set until the sequential rule was satisfied (treat or no-treat decision was reached). When the sequential rule was satisfied, the software calculated the average proportion of infested samples (PI), and the average sample number (ASN), which represents the required sample size over all sampling interactions. The operating characteristic (OC) function also was calculated and the data sets were classified as above or below for each action threshold. The OC expresses the probability of not taking action relative to the true mean of infested plants with S. albicosta egg masses, and ASN expresses the mean sample size required to reach this decision (Naranjo and Hutchison 1997). The impact of the different action thresholds was analyzed using ASN. The OC and ASN were also plotted against the proportion of infested plants from the field data, using TableCurve2D software (Systat Software, Inc. 2002).

Sequential sampling simulations were validated using independent field data for each action threshold and a decision matrix was used as an extension of the validation process (Calvin et al. 1986, Burkness et al. 1999, Burkness and Hutchison 2009). Our decision matrix calculates the probability of making the correct decision (treat or no-treat). First, the observed PI (proportion of plants infested with S. albicosta egg masses) calculated from field data were compared with the action threshold to determine which decision should be made. If PI is greater than the action threshold the decision is to treat. However, if PI is less than the action threshold the decision is to no-treat. Second, the average PI was calculated as an average of infested plants. This number was generated by averaging the resampling results over the 500 resampling bouts. Again, the average PI was compared with the action threshold using the same evaluation as for the observed PI. The third step was the comparison between values of observed PI and average PI and the categorization of the results as follows: 1) observed PI and average PI are larger than the action threshold and the correct decision is to treat; 2) observed PI and average PI are smaller than the action threshold and the correct decision is no-treat; 3) observed PI is smaller than the action threshold but average PI is larger resulting in an incorrect decision to treat; or 4) observed PI is larger than the action threshold but the average PI is smaller resulting in an incorrect decision to no-treat.

Sampling Cost and Final Sampling Plan Selection Criteria. The cost estimates of sampling, considering the time spent to inspect S. albicosta egg masses on corn plants, were obtained by sampling egg masses from five commercial corn fields in Nebraska during 2005. Sampling was conducted by a researcher with previous experience with S. albicosta egg sampling. Considering the practical recommendation of sampling 100 plants per field, the time spent to sample 10 sites with 10 plants each was measured. The mean sampling time, including the time to walk between each sample, is presented in Table 2. Cost estimates are also provided based on current value of hourly labor for crop consultants.

Binomial sampling plan benefits were analyzed using a benefit-cost ratio formula (Burkness et al. 1999, Hodgson et al. 2004, Galvan et al. 2007) as follows:

$$
\text { benefit-cost ratio }=\left[\sum \mathrm{P}_{\mathrm{c}} /(n \times c)\right] \times 100,
$$

where $P_{c}$ is the sum of the overall proportion of correct decisions ( $\mathrm{A}+\mathrm{D}$ column in Table 1$), n$ is the average sample size required to make a decision, and $c$ is the cost of collecting the sample. The cost includes both the time of sampling each plant for egg masses and the time to travel between each sample (Table 2).

For each action threshold, one sampling plan was selected as most appropriate considering the balance among OC, ASN, $\alpha, \beta$ (Table 1 and Fig. 1). The benefit-cost ratio was also considered as a final criterion of sampling plan selection (Table 3).

\section{Results}

Spatial Distribution of Egg Masses. Taylor's Power Law (TPL) regression of the log-mean and log-variance of S. albicosta egg masses densities was highly significant $(P=0.0001)$ with a coefficient of determination $\left(R^{2}\right)$ of 0.99 . The $y$-intercept was 1.13 (SE 0.02 ) and slope was 1.03 (SE 0.01). From the Student $t$-test (SAS Institute 2009), the slope of the regression was not significantly different from $1.0(P>0.05)$, suggesting the egg mass distribution in corn follows a random pattern. No differences were detected between percentage of egg masses found in $B t$ corn (8.4 SD 12.37) and non-Bt corn (5.20 SD 8.15) $(P=0.20)$. Of the total number of plants sampled $(5,640), 540$ were infested with egg masses. Of the infested plants, 85.7\% had one egg mass, $12.2 \%$ had two egg masses, 
Table 1. Probability of correct and incorrect treatment decisions for $S$. albicosta egg mass sampling, with three action thresholds $(4,8,20 \%$ of plants with one or more egg masses each), the estimated proportion of plants infested and operating characteristic (OC)

\begin{tabular}{|c|c|c|c|c|c|c|c|c|c|}
\hline \multicolumn{10}{|c|}{ Action threshold } \\
\hline \multicolumn{2}{|c|}{ Range of variation } & \multirow{2}{*}{ Actual $\alpha$} & \multirow[t]{2}{*}{ Actual $\beta$} & \multicolumn{2}{|c|}{$\begin{array}{l}\text { Correct } \\
\text { decision }\end{array}$} & \multicolumn{2}{|c|}{$\begin{array}{l}\text { Incorrect } \\
\text { decision }\end{array}$} & \multirow{2}{*}{$\begin{array}{l}\text { Total correct } \\
\quad(\mathrm{A}+\mathrm{D})^{e}\end{array}$} & \multirow{2}{*}{$\begin{array}{c}\text { Average sample } \\
\text { no. (ASN) }\end{array}$} \\
\hline Lower bound & Upper bound & & & $\mathrm{A}^{a}$ & $\mathrm{D}^{b}$ & $\mathrm{~B}^{c}$ & $\mathrm{C}^{d}$ & & \\
\hline \multicolumn{10}{|l|}{$4 \%$} \\
\hline 0.01 & 0.07 & 0.03 & 0.03 & 0.400 & 0.405 & 0.018 & 0.176 & 0.805 & 53.2 \\
\hline 0.01 & 0.09 & 0.043 & 0.057 & 0.384 & 0.444 & 0.034 & 0.139 & 0.830 & 40.9 \\
\hline 0.02 & 0.06 & 0.05 & 0.07 & 0.406 & 0.469 & 0.012 & 0.113 & 0.874 & 100.1 \\
\hline \multicolumn{10}{|l|}{$8 \%$} \\
\hline 0.03 & 0.13 & 0.05 & 0.06 & 0.235 & 0.660 & 0.001 & 0.085 & 0.895 & 37.5 \\
\hline 0.04 & 0.12 & 0.062 & 0.075 & 0.254 & 0.685 & 0.0008 & 0.061 & 0.939 & 48.9 \\
\hline \multicolumn{10}{|l|}{$20 \%$} \\
\hline 0.15 & 0.25 & 0.08 & 0.02 & 0.126 & 0.831 & 0.019 & 0.023 & 0.957 & 41.4 \\
\hline 0.16 & 0.24 & 0.088 & 0.007 & 0.118 & 0.843 & 0.009 & 0.030 & 0.961 & 54.5 \\
\hline
\end{tabular}

Final sampling plans selected for each threshold are bolded (see also Table 3).

${ }^{a}$ A, probability of correct decision to treat.

${ }^{b} \mathrm{~B}$, probability of incorrect decision to no-treat.

${ }^{c} \mathrm{C}$, probability of incorrect decision to treat.

${ }^{d} \mathrm{D}$, probability of correct decision to no-treat.

${ }^{e}$ Total probability of correct decision.

$2.0 \%$ had three egg masses, and $0.7 \%$ had four egg masses.

Binomial Sampling. Variation in upper and lower boundaries for each action threshold affected the OC and ASN (Table 1; Fig. 1). Results from Wald's binomial analysis are reported for three action thresholds (4, 8, and 20\%; Table 1). The probability of making correct decisions includes correct decisions to treat (A column) and correct decisions to no-treat (D column). The probability of making incorrect decisions includes incorrect decisions to no-treat (B column) and incorrect decisions to treat ( $\mathrm{C}$ column). These probabilities were calculated from the estimated proportion of plants infested with S. albicosta egg masses, and OC values. The overall proportion of correct decisions are presented in the $\mathrm{A}+\mathrm{D}$ columns for each simulation. For the $4 \%$ threshold, the probabilities to make a correct decision $(\mathrm{A}+\mathrm{D})$ ranged from 0.805 to 0.874 . For the $8 \%$ threshold, the probabilities to make a correct decision $(\mathrm{A}+\mathrm{D})$ ranged from 0.895 to 0.939 . The probabilities of making a correct decision for the $20 \%$ thresholds were quite similar, at 0.957 and 0.961 .

Table 2. Sampling time necessary to search and record $S$. albicosta egg masses in tasseling corn, and estimated costs for a commercial corn field, western Nebraska, 2005

\begin{tabular}{|c|c|c|c|}
\hline $\begin{array}{c}\text { Field } \\
(\text { NE-2005) }\end{array}$ & $\begin{array}{c}\text { No. } \\
\text { sites/field }{ }^{a}\end{array}$ & $\begin{array}{l}\text { Time spent sampling/ } \\
\quad \text { field }(\min )^{b}\end{array}$ & $\begin{array}{c}\text { Hourly cost of } \\
\text { labor (consultants) }\end{array}$ \\
\hline 1 & 10 & 48 & 20.00 \\
\hline 2 & 10 & 41.5 & 17.29 \\
\hline 3 & 10 & 50 & 20.83 \\
\hline 4 & 10 & 58 & 24.17 \\
\hline 5 & 10 & 50 & 20.83 \\
\hline
\end{tabular}

${ }^{a}$ Conducted to provide a total of 100 plants per field (10 sites with 10 plants each).

${ }^{b}$ Mean of sampling time for one sampler with previous experience with S. albicosta egg sampling. This includes time to walk between sample site and the time to inspect 10 consecutive plants for egg masses.

${ }^{c}$ Considering a U.S. crop consultant cost $(\$ 25.00 / \mathrm{h})$.
The average number of plants required to reach either a treat or no-treat decision (ASN) ranged from 37 to 100 plants. For most simulations the ASN ranged from 40 to 55 plants. Only one simulation for the $4 \%$ threshold resulted in an ASN of 100 plants.

The value of $\alpha$ was preset at 0.10 and $\beta$ was preset at 0.05 for all simulations. Actual $\alpha$ and $\beta$ values also were calculated (Table 1). The actual values of $\alpha$ and $\beta$ are variable as a function of the different threshold ranges, inherent variation in the data, and the resampling process (Naranjo and Hutchison 1997). For all thresholds, and all simulations, the actual $\alpha$ values were lower than the value set in the software $(0.10)$. The actual values of $\beta$ varied above and below the value set in the software $(0.05)$.

For the $4 \%$ threshold, the symmetric range of lower and upper bounds of 0.01-0.07 resulted in the lowest actual $\beta(0.03)$ which is below the set value $(0.05)$. In the case of asymmetric range of boundaries around the threshold (0.01-0.09), the actual $\beta$ value $(0.057)$ is greater than the set value; however, the slight difference between the actual and set $\beta$ value is compensated for by a low ASN (40.9 plants). For the 8\% threshold, both simulations resulted in an actual $\beta$ that is greater than the set value. But, again the greater actual $\beta$ is compensated for by ASNs that are $<50 \%$ of the current suggested sample size of 100 plants. For the $20 \%$ threshold, both simulations resulted in an actual $\beta$ less than the set value and the ASN values were much $<100$ plants.

For the $4 \%$ threshold, the simulation with bounds set at 0.01-0.09 was selected as the most appropriate sampling plan (Table 1). The criterion for this selection considered the average of 40.9 plants required to be sampled to make a correct decision with an acceptable value of $A+D$ (0.83). Even though the value of incorrect decisions to no-treat is comparatively larger than the other simulations for the 4\% threshold, this simulation results in an ASN that is $40 \%$ of the 


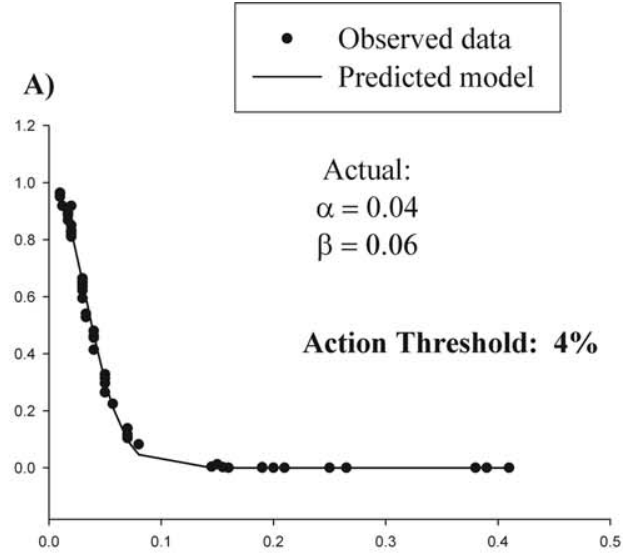

B)

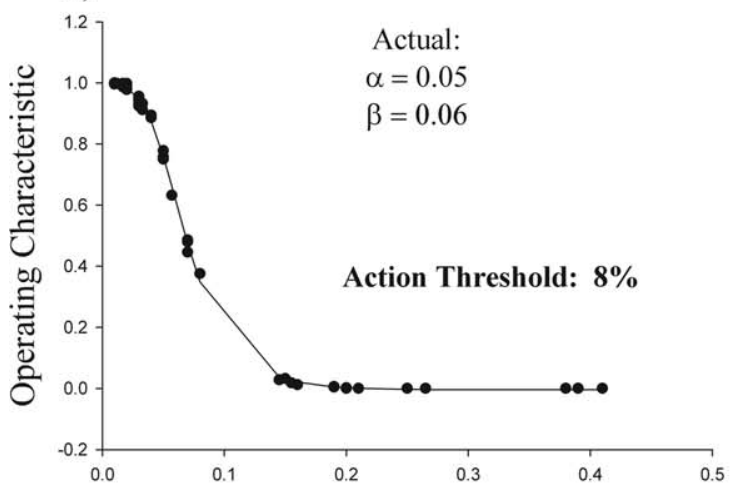

C)

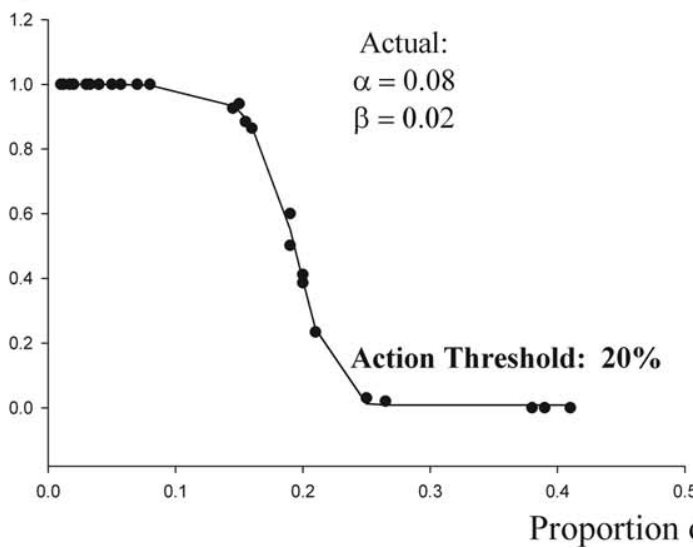

D)

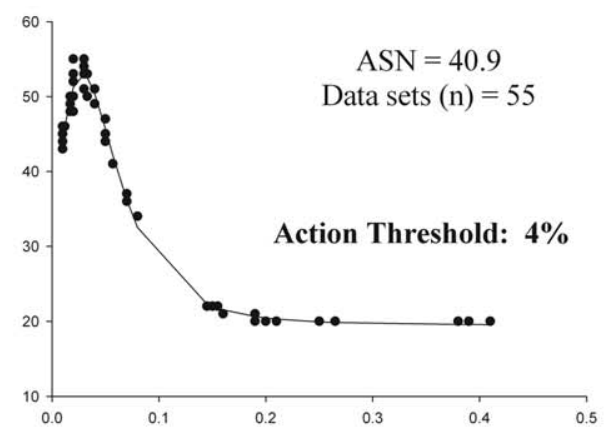

E)

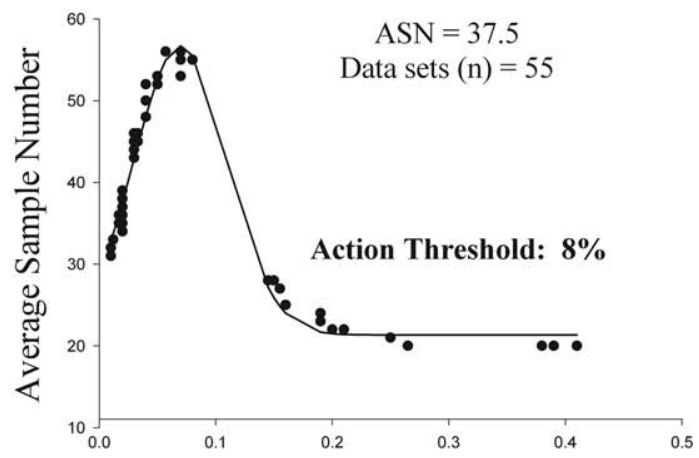

F)

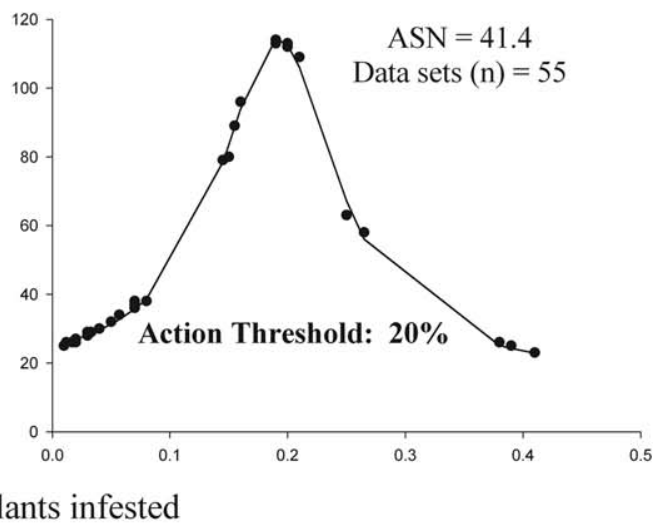

Fig. 1. Operating characteristic (OC) and average sample number (ASN) functions for Wald's sequential probability ratio sampling plan, considering 4, eight and $20 \%$ S. albicosta action thresholds (i.e., percentage of plants with one or more egg masses each). The OC and ASN were plotted against the observed proportion infested based on resampling validation (RVSP software) using field data. Predicted models were fitted using equation 8189 from Table Curve for A, B, C, and D. Predicted models in $\mathrm{E}$ and $\mathrm{F}$ used equation 8003 and 8004, respectively. The actual $\alpha$ and $\beta$ values are presented on each graph (A-C).

current suggested sample size of 100 plants. For the $8 \%$ threshold, the ASN values for both simulations decreased the number of plants to be sampled (38 and 49 plants) (Table 1). If the decision criterion was only based on the large value of the total correct decision (A+D) (Burkness et al. 1999), the simulation with a range of variation of $0.04-0.12$ seems to be the most appropriate (Table 1). For the 20\% threshold, the simulation with a range of variation of $0.15-0.25$ was selected as the most appropriate (Table 1). The correct decision values were only slightly different, but the ASN was reduced by 13 plants. 
Table 3. Comparison of efficiency of the binomial sampling plans for S. albicosta egg masses based on the benefit-cost ratio criterion

\begin{tabular}{|c|c|c|c|c|c|}
\hline \multicolumn{6}{|c|}{ Action threshold } \\
\hline \multicolumn{2}{|c|}{ Sampling plan } & \multirow{2}{*}{$\begin{array}{l}\text { Average sample } \\
\text { no. (ASN) }\end{array}$} & \multirow{2}{*}{$\begin{array}{l}\text { Total correct decisions } \\
(\text { proportion })(\mathrm{A}+\mathrm{D})^{a}\end{array}$} & \multirow{2}{*}{$\begin{array}{c}\text { Average sample } \\
\text { time/plant (minutes) }{ }^{b}\end{array}$} & \multirow{2}{*}{$\begin{array}{l}\text { Benefit-cost } \\
\text { ratio }^{c}\end{array}$} \\
\hline Lower bound & $\overline{\text { Upper bound }}$ & & & & \\
\hline \multicolumn{6}{|l|}{$4 \%$} \\
\hline 0.01 & 0.07 & 53.2 & 0.805 & 0.495 & 3.06 \\
\hline 0.01 & 0.09 & 40.9 & 0.830 & 0.495 & 4.09 \\
\hline 0.02 & 0.06 & 100 & 0.874 & 0.495 & 0.01 \\
\hline \multicolumn{6}{|l|}{$8 \%$} \\
\hline 0.03 & 0.13 & 37.5 & 0.895 & 0.495 & 4.82 \\
\hline 0.04 & 0.12 & 48.9 & 0.939 & 0.495 & 3.88 \\
\hline \multicolumn{6}{|l|}{$20 \%$} \\
\hline 0.15 & 0.25 & 41.4 & 0.957 & 0.495 & 4.67 \\
\hline 0.16 & 0.24 & 54.5 & 0.961 & 0.495 & 3.56 \\
\hline
\end{tabular}

Final sampling plans selected, parameters and sampling effort for each threshold are bolded.

${ }^{a}$ Probability of correct decisions (see Table 1).

${ }^{b}$ Sampling time of one plant, including the mean time to walk between plants and among sites (see Table 2).

${ }^{c}$ Benefit-cost ratio $=\left[\Sigma \mathrm{P}_{\mathrm{c}} /(n \times c)\right] \times 100$, where $\mathrm{P}$ is the sum of proportional correct decisions, $n$ is the average number of samples required to make a decision, and $c$ is the cost (expressed in time) of sampling the egg masses in corn plants (Galvan et al. 2007).

Sampling Cost and Final Sampling Plan Selection Criteria. The average sample time required to evaluate one plant (Table 2 ) was $0.49 \mathrm{~min}$. This average time to sample one corn plant was used in the benefit-cost ratio formula and summarized for each sampling plan simulation (Table 3). The final simulation selected, for the $4 \%$ threshold sampling plan, reduced sampling cost by $60 \%$ (ASN $=40.9$ plants), compared with the current 100 plant sampling recommendation (Table 1). This plan also had the larger benefit-cost ratio (4.09) (Table 3). In the same way, the selected simulation for the $20 \%$ threshold sampling plan resulted in a reduced number of plants required to be sampled (ASN $=41.4$ plants) and a high benefit-cost ratio (4.67) (Table 3). In the simulations for the $8 \%$ threshold there was a trade-off between precision and efficiency (Galvan et al. 2007). As presented previously, if the criteria of sampling plan selection is only based on the total probability of correct decision $(\mathrm{A}+\mathrm{D})$, the most appropriate sampling plan is the simulation with a range of variation from 0.04 to $0.12(0.939)$, with an increase in ASN (48.9 plants) (Table 3). In contrast, the higher benefit-cost ratio (4.82) indicated that the sampling plan for the $8 \%$ threshold with the lower number of the sampled plants (ASN $=38$ plants) is most favorable (Table 3). The final decision considered the practical aspects related with the cost-efficiency.

The OC and ASN functions are plotted against observed proportion of infested plants with S. albicosta egg masses for each selected simulation, which represents a better balance between all parameters discussed previously (Fig. 1).

Stop lines were calculated for each of the sampling plan validated (Fig. 2). For each plan the decision to treat should be adopted if the cumulative number of plants with one or more $S$. albicosta egg masses is above the upper line. Conversely, control measures should not be implemented if the cumulative number of plants with one or more S. albicosta egg masses is below the lower line. In situations where the cumulative number of plants with one or more S. albicosta egg masses is between the two stop lines, additional samples are required before reaching a final treatment decision (Pedigo and Zeiss 1996). For each threshold the intercept of the lower stop line on the $\mathrm{x}$-axis indicates the minimum number of plants that are required to sample to allow both treat and no-treat decisions to be made (Fig. 2). At least 35 plants are necessary to be sampled to make a decision when the threshold is $4 \%$. For the 8 and $20 \%$ threshold, at least 27 and 23 plants are required to be sampled, respectively.

\section{Discussion}

In this study, sampling plans for three different $S$. albicosta action thresholds were developed and validated using resampling software based on Wald's binomial sampling plan (Naranjo and Hutchison 1997). The egg mass data represented a range of high, medium, and low egg densities, conducive for resampling analysis (Burkness and Hutchison 2009).

In all simulations, the probability of making a correct decision was always at least $80 \%$. The ASN in all but one case produces a reduction of the current practical recommendation of 100 corn plants. Only in one simulation for the $4 \%$ threshold did the ASN equal the current recommendation. Moreover, the benefitcost ratio demonstrated that the reduction of the number of the sampled plants is followed by an increase of cost-efficiency. Only in the case of the $8 \%$ threshold there is a trade-off between precision and efficiency (Galvan et al. 2007) and the final decision in selection of the sampling plan was considering the lower number of plants required to be sampled.

The selection of the most appropriate simulation for each threshold should consider the balance among $\mathrm{OC}, \mathrm{ASN}, \alpha, \beta$ and the benefit-cost ratio. However, in general it is possible to conclude that 40 represented an appropriate average number of plants required to reach either a treat or no-treat decision.

The actual $\alpha$ value (Table 1 ) is lower than the preset value of 0.10 in all simulations and represents a reduction of a type I error (adopting a control action when it is not necessary). In the case of $\beta$ values, most binomial sampling plan studies set this variable at 0.10 

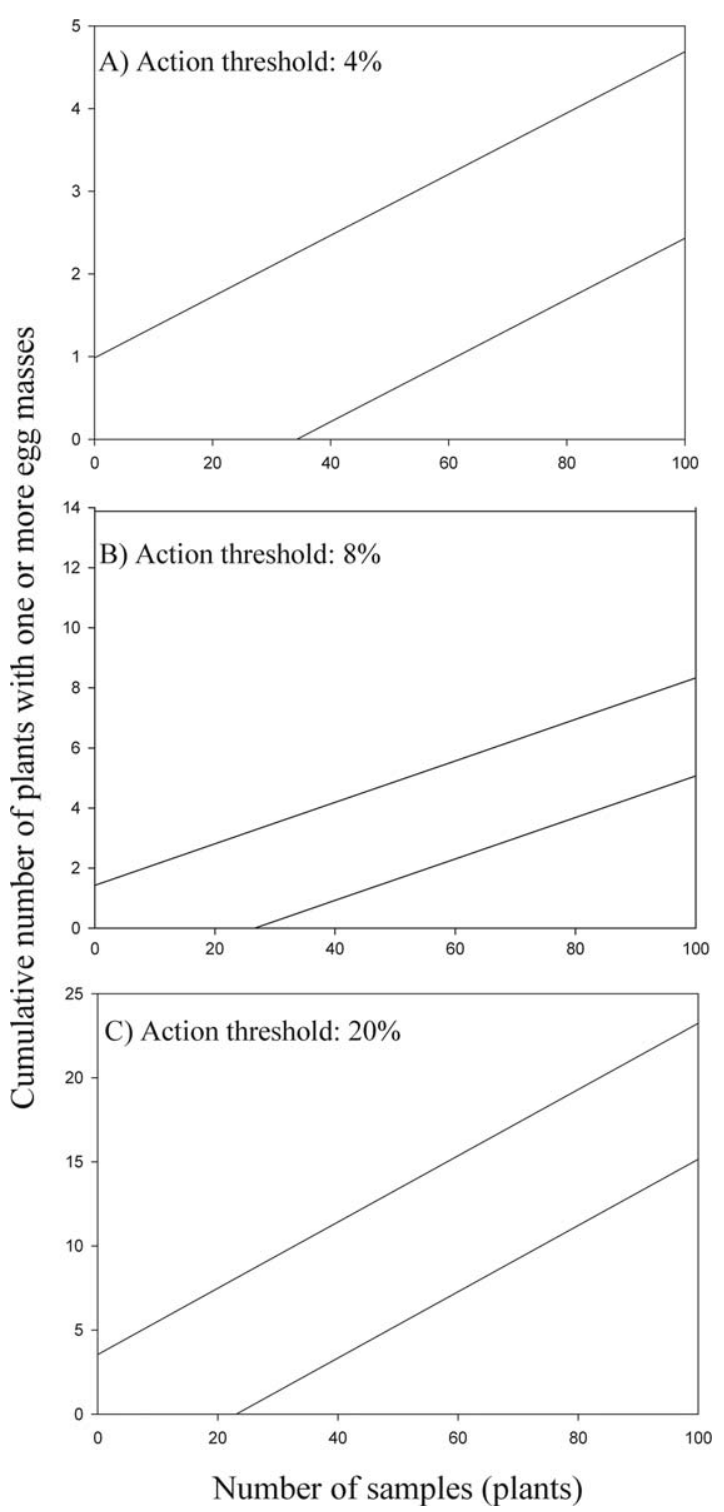

Fig. 2. Stop-lines for binomial sequential sampling plans considering 4, eight and 20\% action thresholds for S. albicosta egg masses in corn. Equations for $4 \%$ action threshold: upper line is $y=0.99+0.04 x$ and lower line is $y=-1.27+0.04$ $x$; equations for $8 \%$ action threshold: upper line is $y=1.43+$ $0.4 x$ and lower line is $y=-1.83+0.07 x$; equations for $20 \%$ action threshold: upper line is $y=3.54+0.2 x$ and lower line is $y=-4.54+0.2 x$.

(Jones 1994, Naranjo and Hutchison 1997); however, for simulations in this study the $\beta$ value was set at 0.05 . The reduced $\beta$ value promoted an overall increase of the ASN in all simulations, but this also decreased the probability of a type II error (control actions are not taken when necessary). This risk is critical in the adoption of sampling plans for any crop because it represents the risk of potential economic losses. In the current study, the thresholds for S. albicosta egg masses are action thresholds (based primarily on expe- rience, not threshold-specific research) and were based on considerable field experience from consultants and extension personnel (Seymour et al. 2004, Peairs 2006, Rice 2007, Cullen and Jyuotika 2008). However, because these thresholds are action thresholds, and used over broad regions without significant consideration of market values (Pedigo and Rice 2009) and validation from research data, a conservative $\beta$ is appropriate. The actual $\beta$ value in any case was always below 0.10 with the highest value at 0.075 (Table 1 ).

In all graphical representations of ASN versus the proportion of infested plants (Fig. 1D, 1E, and $1 \mathrm{~F}$ ), the greatest ASN values are near the action thresholds. These results exemplify one of the most interesting characteristics of a binominal sampling plan, which is that the number of samples will be related to the density of the pest population (Jones 1994). In other words, at low and high pest densities, either no-treat or treat decisions will be indicated after a relatively low number of samples. In addition to the increase in efficacy of sampling programs, another advantage of binomial sampling plans is that the categorization of the pest as presence or absence reduces the effect of unusual values in a sample when compared with enumerative analysis, where measures of population density are made (Jones 1994). Evaluation of S. albicosta egg masses based on presence or absence is an appropriate approach, because it saves time and increases the efficacy of detection, especially considering that majority of the infested corn plants in the 70 fields sampled in this study were infested with one egg mass per plant.

The OC function was calculated for each sampling plan considering each different action threshold and its selected range of variation. Besides being used in a decision matrix to calculate correct and incorrect decisions, it is also plotted against the observed proportion of infested plants (Fig. 1A, 1B, and 1C). According to Naranjo and Hutchison (1997), when $\alpha$ and $\beta$ are equal, the $\mathrm{OC}$ value would be ideally equal to 0.5 when at the action threshold value. The OC for the sampling plan for the $4 \%$ threshold simulated with the asymmetric range of variation was 0.46 , which is a near 0.5 (Fig. 1A). For the sampling plan with the $8 \%$ threshold with a 0.04 variation range, the $\mathrm{OC}$ was 0.34 (Fig. 1B), and the OC for the sampling plan for the $20 \%$ threshold with a 0.04 variation range was 0.4 (Fig. 1C). Therefore, in all three sampling plans the probability of a no-treat decision was lower than 50\%. This means that the sampling plans for the 8 and $20 \%$ thresholds could be considered conservative and when at the threshold it is more likely that you will make a treat decision than a no-treat decision (Galvan et al. 2007).

In Fig. 2, the stop lines indicate that there are three different decision choices for each action threshold and the cumulative number of samples required to make a decision will depend on the action threshold for each sampling plan. For the $4 \%$ threshold, sampling at least 35 plants will be necessary before reaching a decision (intersection of lower bound) (Fig. 2A). For the 8 and $20 \%$ thresholds the minimum numbers of samples are 27 and 23 , respectively (Fig. $2 \mathrm{~B}$ and C). However, it is important to consider the time required 
to sample when the infestation level of the pest is in between the upper and lower stoplines. Binns (1994) highlights the necessity to set a time limit in this zone. In the case of soybean aphid it is not recommended to take $>31$ samples to make a control decision (Hodgson et al. 2004). This resampling period should be based on the development time of the pest species. The current $S$. albicosta egg mass sampling recommendation of 100 plants can serve as a sampling limit, when necessary, if egg mass counts fall within the stoplines.

Correct timing of sampling is critical and should not be initiated before the pest population is active or after the pest damage has become unacceptable (Higley and Peterson 1994); for S. albicosta, management intervention must occur before larvae enter the ear. Because S. albicosta has one generation per year (Antonelli 1974), it would be opportune to associate the sequential binomial sampling plan proposed in this work with other research on the degree-days required for adult emergence and adult field trapping techniques (Dorhout and Rice 2008). For example, Holtzer (1983) found the relationship between S. albicosta light trap catches and the presence of egg masses was consistent in timing and magnitude. Therefore, by using moth counts from light trap the efficiency of S. albicosta egg mass sampling can be further improved.

For S. albicosta, there is a narrow treatment window between egg hatch and ear colonization, so detection of a possible economic population during the egg stage is critical to apply control measures before larvae enter the ear. Moreover, considering the behavioral characteristics of larvae (e.g., early instars spend time concealed in the whorl or leaf axil), sampling plans that evaluate egg mass density are more appropriate than sampling the larvae (Seymour et al. 2004).

Knowledge of the dispersion of a pest is important to determine the optimal sampling pattern in the field (Hutchison 1994). The TPL regression analysis of $S$. albicosta indicated the egg mass distribution in the field is random, with the slope of the linear equation equal to 1 . This indicates that the probability is equal throughout the cornfield for a plant to receive an $S$. albicosta egg mass. In this way, the spatial sampling pattern should be random across a cornfield, and every sampling site should have the same chance to be selected. Establishing one sampling transect through a cornfield (Pedigo and Rice 2009) would be an appropriate option, with periodical evaluations of corn plants along the route. However, planting date, hybrid maturity, and even differences in corn development in the same field should be considered in the division of the sampling sites, because these factors may influence the attractiveness of the plants and deposition of the egg masses.

One other variable that could influence the spatial distribution of the egg masses is the effect of $B t$ hybrids. However, our data indicated that there were no differences in oviposition by $S$. albicosta females on $B t$ or no-Bt corn, even though Cryl F has efficacy on $S$. albicosta larvae (Eichenseer et al. 2008).
The binomial sequential sampling plans for S. albicosta developed here will significantly reduce the time and effort required for effective management of this pest; however, because they are based on action thresholds, not thoroughly researched economic thresholds, and because much is unknown about the pest's biology and behavior across ecozones, there is the potential for improvement. Future research describing the yield-loss relationships for S. albicosta in corn would provide more accurate thresholds for sampling plan development, and future studies investigating the role of larval survival (Ostlie and Pedigo 1987) across ecozones could provide information that could be incorporated into the management decision matrix, such as that used to make control decisions for second generation Ostrinia nubilalis (Hübner) (Wright 2007).

\section{Acknowledgments}

We thank Pioneer Hi-Bred International Crop Management Research Award, USDA NC IPM Program Proposal No. 2008-01824, Embrapa Agrofuturo, and Keith Flint for his technical support through the field sampling process.

\section{References Cited}

Antonelli, A. L. 1974. Resistance of Phaseolus vulgaris cultivars to western bean cutworm, Loxagrotis albicosta (Smith), with notes on the bionomics and culture of the cutworm. Ph.D. dissertation, University of Idaho, Moscow, ID.

Appel, L. L., R. J. Wright, and J. B. Campbell. 1993. Economic injury levels for western bean cutworm, Loxagrotis albicosta (Smith) (Lepidoptera: Noctuidae), larvae in field corn. J. Kans. Entomol. Soc. 66: 434-438.

Binns, M. R. 1994. Sequential sampling for classifying pest status, pp. 137-174. In L. Pedigo and G. Buntin (eds.), Handbook of sampling methods for arthropods in agriculture. CRC, Boca Raton, FL.

Binns, M. R., J. P. Nyrop, and W. van der Werf. 2000. Sampling and monitoring in crop protection - the theoretical basis for developing practical decision guides. CABI publishing, Wallingford, United Kingdom.

Burkness, E. C., and W. D. Hutchison. 2009. Implementing reduced-risk integrated pest management in fresh-market cabbage: influence of sampling parameters, and validation of binomial sequential sampling plans for the cabbage looper (Lepidoptera: Noctuidae). J. Econ. Entomol. 102: 1874-1883.

Burkness, E. C., R. C. Venette, P. K. O'Rourke, and W. D. Hutchison. 1999. Binomial sequential sampling for management of aster leafhopper (Homoptera: Cicadellidae) and aster yellows phytoplasma in carrot: impact of tally threshold on the accuracy of treatment decisions. Environ. Entomol. 28: 851-857.

Calvin, D. D., M. C. Knapp, K. Xingquan, F. L. Poston, and S. M. Welch. 1986. Using a decision model to optimize European corn borer (Lepidoptera: Pyralidae) egg-mass sampling. Environ. Entomol. 15: 1212-1219.

Cullen, E., and J. Jyuotika. 2008. Western bean cutworm: a pest of sweet corn. A3856, University of Wisconsin Extension, Cooperative Extension. (http://learningstore. uwex.edu/pdf/A3856.pdf).

DiFonzo, C. D., and E. Cullen. 2010. Handy Bt trait table. University of Wisconsin Extension, Field Crops Entomol- 
ogy MSU Program. (http://www.entomology.wisc.edu/ cullenlab/publications/pdf).

DiFonzo, C. D., and R. Hammond. 2008. Range expansion of western bean cutworm, Striacosta albicosta (Noctuidae), into Michigan and Ohio. Crop Manag. doi:10.1094/ CM-2008-0519-01-B. (http://msuent.com/assets/ DiFonzoHammondWBC.pdf).

Dorhout, D. L., and M. E. Rice. 2004. First report of western bean cutworm, Richia albicosta (Noctuidae) in Illinois and Missouri. Crop Manag. DOI:10.1094/CM-2004-1229-01BR. (http://www.plantmanagementnetwork.org/pub/cm/ brief/2004/cutworm).

Dorhout, D. L., and M. E. Rice. 2008. An evaluation of western bean cutworm pheromone trapping techniques (Lepidoptera: Noctuidae) in a corn and soybean agroecosystem. J. Econ. Entomol. 101: 404-408.

Douglass, J. R., J. W. Ingram, K. E. Gibson, and W. E. Peay. 1957. The western bean cutworm as a pest of corn in Idaho. J. Econ. Entomol. 50: 543-545.

Eichenseer, H., R. Strohbehn, and J. Burks. 2008. Frequency and severity of western bean cutworm (Lepidoptera: Noctuidae) ear damage in transgenic corn hybrids expressing different Bacillus thuringiensis cry toxins. J. Econ. Entomol. 101: 555-563.

Galvan, T. L., E. C. Burkness, and W. D. Hutchison. 2007. Enumerative and binomial sequential sampling plans for the multicolored Asian lady beetle (Coleoptera: Coccinellidae) in wine grapes. J. Econ. Entomol. 100: 1000 1010.

Hagen, A. F. 1962. The biology and control of the western bean cutworm in dent corn in Nebraska. J. Econ. Entomol. 55: 628-631.

Higley, L. G., and R.K.D. Peterson. 1994. Initiating sampling programs, pp. 119-136. In L. Pedigo and G. Buntin (eds.), Handbook of sampling methods for arthropods in agriculture. CRC, Boca Raton, FL.

Hodgson, E. W., E. C. Burkness, W. D. Hutchison, and D. W. Ragsdale. 2004. Enumerative and binomial sequential sampling plans for soybean aphid (Homoptera: Aphididae) in soybean. J. Econ. Entomol. 97: 2127-2136.

Hoerner, J. L. 1948. The cutworm Loxagrotis albicosta on beans. J. Econ. Entomol. 41: 631-635.

Holtzer, T. O. 1983. Distribution of western bean cutworm eggs among short-, mid-, and long-season corn hybrids planted on different dates. Environ. Entomol. 12:1983. 1375-1379.

Hutchison, W. D. 1994. Sequential sampling to determine population density, pp. 207-244. In L. Pedigo and G. Buntin (eds.), Handbook of sampling methods for arthropods in agriculture. CRC, Boca Raton, FL.

Hutchison, W. D., E. C. Burkness, P. D. Mitchell, R. D. Moon T. W. Leslie, S. J. Fleischer, M. Abrahamson, K. L. Hamilton, K. L. Steffey, M. E. Gray, et al. 2010. Areawide suppression of European corn borer with Bt maize reaps savings to non-Bt maize growers. Science 330: 222-225.

Jones, V. P. 1994. Sequential estimation and classification procedures for binomial counts, pp. 175-205. In L. Pedigo and G. Buntin (eds.), Handbook of sampling methods for arthropods in agriculture. CRC, Boca Raton, FL.

Kuno, E. 1991. Sampling and analysis of insect populations. Annu. Rev. Entomol. 36: 285-304.

Michel, A. P., C. H. Krupke, T. S. Baute, and C. D. DiFonzo. 2010. Ecology and management of the western bean cut- worm (Lepidoptera: Noctuidae) in corn and dry beans. J. Integr. Pest Manag. 1:A1-A10. DOI: 10.1603/IPM1003.

Miller, N. J., D. L. Dorhout, M. E. Rice, and T. W. Sappington. 2009. Mitochondrial DNA variation and range expansion in western bean cutworm (Lepidoptera: Noctuidae): no evidence for a recent population bottleneck. Environ. Entomol. 38: 274-280.

Naranjo, S. E., and W. D. Hutchison. 1997. Validation of arthropod sampling plans using a resampling approach: software and analysis. Am. Entomol. 43: 48-57.

Nault, B. A., and A. M. Shelton. 2010. Impact of insecticide efficacy on developing action thresholds for pest management: a case study of onion thrips (Thysanoptera: Thripidae) on onion. J. Econ. Entomol. 103: 1315-1326.

O'Rourke, P. K., and W. D. Hutchison. 2000. First report of the western bean cutworm Richia albicosta (Smith) (Lepidoptera: Noctuidae), in Minnesota corn. J. Agric. Urban Entomol. 17: 213-217.

Ostlie, K. R., and L. P. Pedigo. 1987. Incorporating pest survivorship into economic thresholds. Bull. Entomol. Soc. Am. 1987. 33: 98-102.

Peairs, F. B. 2006. Western bean cutworm: characteristics and management in corn and dry beans. Colorado State University Extension. 3/02.n. 5.5538. (http://www.ext. colostate.edu/pubs/insect/05538.html).

Pedigo, L. P., and M. E. Rice. 2009. Entomology and pest management. Prentice Hall, NJ.

Pedigo, L. R., and M. R. Zeiss. 1996. Analyses in insect ecology and management. Iowa State University Press, Ames, IA.

Rice, M. E. 2000. Western bean cutworm hits northwest Iowa. Integrated Crop Mgt. IC-484(22): 163. Iowa State University Extension, Ames, IA. (http://www.ipm. iastate.edu/ipm/icm/2000/9-18-2000/wbcw.html).

Rice, M. E. 2006. Eastern movement of the western bean cutworm into Indiana and Ohio. Proceedings: Indiana CCA Conference, Indianapolis, IN.

Rice, M. E. 2007. Economic thresholds for western bean cutworms. Iowa State University Extension, Ames, IA. (http://www.ipm.iastate.edu/ipm/icm/2007/7-2/ wbcth.html).

SAS Institute. 2009. SAS user's guide: statistics, version. 9.1.3. SAS Institute, Cary, NC.

Seymour, R. C., G. L. Hein, R. J. Wright, and J. B. Campbell. 2004. Western bean cutworm in corn and dry beans. Neb. Coop. Ext. Guide G1359. Lincoln, NE.

Systat Software, Inc. 2002. TableCurve 2D v5.01 for Windows, 2002. Systat Software, Inc., San Jose, CA.

Taylor, L. R. 1961. Aggregation, variance and the mean. Nature (Lond.) 189: 732-735.

Tooker, J. F., and S. J. Fleischer. 2010. First report of western bean cutworm (Striacosta albicosta) in Pennsylvania. Crop Mgmt. DOI: 10.1094/CM-2010-0616-01-RS.

Young, L. J., and J. H. Young. 1998. Statistical ecology: a population perspective. Kluwer Academic, Boston, EUA.

Wald, A. 1947. Sequential analysis. Wiley, New York.

Wright, R. J. 2007. Second generation European corn borer scouting and treatments decisions. University of $\mathrm{Ne}$ braska Ext. Neb Guide G1783. Lincoln, NE.

Received 21 April 2011; accepted 6 August 2011. 